\title{
Renal Denervation in the Most Serious Form of Resistant Arterial Hypertension
}

\author{
J. ŠOCHMAN ${ }^{1}$, M. BÜRGELOVÁ ${ }^{2}$, J. H. PEREGRIN ${ }^{2}$ \\ ${ }^{1}$ Department of Cardiology, Institute for Clinical and Experimental Medicine, Prague, Czech \\ Republic, ${ }^{2}$ Department of Diagnostic and Interventional Radiology, Institute for Clinical and \\ Experimental Medicine, Prague, Czech Republic
}

Received October 15, 2015

Accepted April 15, 2016

On-line August 19, 2016

\section{Summary}

The aim of our observation was to establish whether or not renal sympathetic denervation (RSD) may help control blood pressure (BP) levels in patients with severe hypertension refractory to pharmacological therapy. Out of a group of 12 patients, candidates for RSD, with uncontrolled hypertension and a systolic BP over $190 \mathrm{~mm} \mathrm{Hg}$ on repeated measurements despite optimal medication, four patients were excluded for multiple renal arteries and one for hyperaldosteronism. Seven patients had RSD using a Symplicity device (5M, 2 F) with a mean age of 64.9 years. While all were followed up for a minimum of 6 months, follow-up duration in the majority of them was substantially longer (12-20 months). At six months post-RSD, six of the seven patients showed a decrease in systolic BP by at least $15 \mathrm{~mm} \mathrm{Hg}$ while receiving the same or fewer doses of antihypertensive agents. A similar response was seen in diastolic BP. The BP decrease was maintained throughout whole followup. In a small group of patients with severe hypertension, we demonstrated that renal sympathetic denervation is capable of reducing blood pressure even in patients with severe hypertension.

\section{Key words}

Hypertension - Renal symphatetic denervation - Symplicity device $\bullet$ Uncontrolled blood pressure

\section{Corresponding author}

J. H. Peregrin, Department of Diagnostic and Interventional Radiology, Institute for Clinical and Experimental Medicine, Vídeňská 1958/9, 14021 Prague 4, Czech Republic. Fax: +420241723251. E-mail: jape@ikem.cz, jan.peregrin@seznam.cz

\section{Introduction}

Renal sympathetic denervation (RSD) in resistant arterial hypertension has recently been a hotly debated topic. While, based on data from the SYMPLICITY HTN-1 and SYMPLICITY HTN-2 trials, investigators pinned hopes on RSD as an option in the treatment of hypertension, conclusions of the subsequent SYMPLICITY HTN-3 trial brought about disillusionment. To date, unanimity has not been reached regarding its efficacy, with opinions ranging from completely positive to completely negative (Krum et al. 2009, Esler et al. 2010, Kandzari et al. 2012, Bhatt et al. 2014). Still, while it is almost certain that there are patients who may benefit from RSD, we are apparently not yet able to reliably identify this specific patient population. The aim of our study was to find out whether it is possible to identify, even among those with the most severe forms of hypertension, patients who would respond to this technique at all. Systolic blood pressure decrease by at least $15 \mathrm{~mm} \mathrm{Hg}$ was considered as positive response.

\section{Material and Methods}

In our limited group of patients, RSD was performed using a Symplicity device (Medtronic, Mountain View, CA, USA). We sought to select patients experiencing major clinical problems with the antihypertensive therapy. These patients were characterized by long-term follow-up in an outpatient 
clinic of cardiology before their inclusion in the group selected for RSD. They had to meet the usual requirements of use of a combination of several antihypertensive drugs; also, they had to repeatedly have systolic blood pressure (SBP) levels above $200 \mathrm{~mm} \mathrm{Hg}$ as measured by professional health workers and a documented episode of hypertensive crisis. To rule out a potential secondary cause of arterial hypertension, all these patients had basic laboratory tests and whenever possible, ambulatory blood pressure monitoring (ABPM), echocardiography, renal artery CTA with simultaneous visualization and evaluation of renal parenchyma. Irrespective of the documented highest blood pressure (BP) levels and their fluctuations, the baseline value used in subsequent comparisons was that measured closest to the date of the procedure. In 2012, when RSD was introduced in our center, we identified a total of 11 patients. Prior to becoming candidates for RSD, they were individuals followed up on an outpatient basis in our department (these patients were demonstrably compliant to proper use of medication) while also meeting anatomical criteria for RSD (see below).

Actual RSD was performed in all patients meeting all criteria for inclusion in the study and signing informed consent. The renal variables monitored on a regular basis included changes in glomerular filtration rate (GFR- $\mathrm{C}_{\mathrm{cr}}$, GFR-MDRD), serum creatinine $\left(\mathrm{S}_{\mathrm{cr}}\right)$, urea, urinary albumin/creatinine ratio $\left(\mathrm{U}_{\mathrm{alb}} / \mathrm{cr}\right), 24-\mathrm{h}$ urinary sodium and potassium excretion $\left(\mathrm{U}_{\mathrm{Na}} \mathrm{V}, \mathrm{U}_{\mathrm{K}} \mathrm{V}\right)$, fraction excretion of sodium and potassium $\left(\mathrm{FE}_{\mathrm{Na}}, \mathrm{FE}_{\mathrm{K}}\right)$, and urinary $\mathrm{Na} / \mathrm{K}$ ratio $\left(\mathrm{U}_{\mathrm{Na}} / \mathrm{U}_{\mathrm{K}}\right)$. Further, we sought to find out whether RSD, performed in patients with such an extreme degree of hypertension, can affect the levels of some novel biomarkers reflecting processes within the cardiovascular system (Sun et al. 2014). Hence, we also focused our attention on proatrial natriuretic peptide (proANP), midregional proadrenomedullin (proADM), and copeptin (COP).

\section{Patient characteristics}

Based on their clinical status as specified above, a total of 12 patients were initially selected since 2012 . Four patients were excluded because of their renal vascular anatomy, with multiple renal arteries (measuring $\leq 4 \mathrm{~mm}$ in diameter) currently not recommended to catheter-based ablation (Krum et al. 2009, Esler et al. 2010, Kandzari et al. 2012, Bhatt et al. 2014), in one patient a micronodular primary hyperaldosteronism was found. The remaining group of seven patients included
5 men and 2 women, with a mean age of 64.9 years at the time of RSD. Table 1 presents more detailed patient characteristics.

Table 1. Characteristics of 7 patients with resistant hypertension who underwent RSD.

\begin{tabular}{lc}
\hline Gender M/F & $5 / 2$ \\
Mean age (range, 61-68), years & 64.9 \\
Average BMI, $\mathrm{kg} / \mathrm{m}^{2}$ & $32.3 \pm 4.5$ \\
Medication & \\
$\beta$-blocker & $7 / 7$ \\
Angiotensin receptor blocker & $7 / 7$ \\
Calcium-channel blocker & $6 / 7$ \\
$\alpha_{1}$ adrenergic receptor blocker & $5 / 7$ \\
$\alpha$ blocker+central 5HT receptor agonist & $4 / 7$ \\
Diuretic & $7 / 7$ \\
Comorbidities, $n /$ patients & $5 / 7 *$ \\
Mean creatinine ( $\mu$ mol/l) & $86.7 \pm 15.9$ \\
Mean cholesterol (mmol/l) & $5.25 \pm 0.7$ \\
Mean glycemia (mmol/l) & $5.65 \pm 0.45$ \\
Mean COP (pmol/l) & $7.26 \pm 3.55 \#$ \\
Mean proADM (nmol/l) & $0.67 \pm 0.15 \#$ \\
Mean proANP (pmol/l) & $118.59 \pm 55.14 \#$ \\
\hline
\end{tabular}

BMI - body mass index, 5HT - 5-hydroxytryptamine, COP copeptin, proADM - proadrenomedullin, proANP - pronatriuretic peptide. * Comorbidities: AAA - abdominal aortic aneurysm, MS - metabolic syndrome with overweight, SL - solitary kidney, CAD - coronary artery disease, $\mathrm{O}$ - obesity. \# No change in levels at follow-up visits.

The pharmacotherapy instituted prior to RSD should be considered optimal as the patients had been previously receiving other drugs and combinations thereof but did not tolerate them. Essentially, all patients were taking a $\beta$-blocker (metoprolol at a dose of $100-300 \mathrm{mg} / \mathrm{day})$, an angiotensin-receptor blocker (predominantly telmisartan at doses of $80-160 \mathrm{mg} /$ day), and a diuretic (hydrochlorothiazide at an average dose of $25 \mathrm{mg}$ /day). Add-on therapy included a selective inhibitor of $\alpha_{1}$ subtype of $\alpha$-adrenergic receptors (doxazosin), $\alpha_{1}$-adrenoceptor antagonist with central agonistic action at serotonin $5-\mathrm{HT}_{1 \mathrm{~A}}$ receptors (urapidil), and calciumchannel blockers. Those additional drugs were uptitrated to maximum tolerated doses (specifically, the highest doses of doxazosin and urapidil were $8 \mathrm{mg}$ and $180 \mathrm{mg}$, respectively). Comorbidities included cases of suprarenal ulceration/abdominal aortic aneurysm (managed by endovascular approach immediately prior to RSD), 
atrial fibrillation (paroxysmal, resolving after BP normalization), and metabolic syndrome with coronary arterial disease. One patient undergoing RSD with coronary arterial disease and metabolic syndrome had a solitary kidney. In principle, all patients were classified as overweight to degree I obesity, with a BMI $\geq 35$ in two patients.

The mean level of office SBP was 170.9 $( \pm$ SD 15.0) $\mathrm{mm} \mathrm{Hg}$ (the primary focus on SBP was because of the greater impact of the catecholaminergic system on subsequent RSD outcome). The mean value of SBPA derived from ambulatory BP monitoring (ABPM) (overall in-study value; unfortunately unavailable from all patients in our group) was $158.2 \mathrm{~mm} \mathrm{Hg}$ ( \pm SD 10.2). On average, the patients were taking combinations of five drugs ( \pm SD 0.9). Follow-up visits were scheduled at 3, 6, and 12 months post-RSD, with follow-up still under way.

\section{Description of procedure}

A $6 \mathrm{~F}$ guiding catheter was manipulated from the femoral artery approach to the renal artery ostium and a radiofrequency $(\mathrm{RF})$ catheter was introduced into the artery lumen (Symplicity, Medtronic, Mountain View, CA, USA). All procedures were performed in analgosedation. All patients were heparinized to reach an ACT level of 200-250 s. The Symplicity catheter tip was advanced as distally to the main renal artery as the anatomy allowed and the tip of the catheter was brought into contact with the renal artery endothelium. Five to eight RF ablations were performed, after each ablation the catheter was rotated and slightly withdrawn within the lumen of the renal artery. The tip of the catheter reached a temperature of $58-69^{\circ} \mathrm{C}$. Since the relationship between the RF generator output and the tip catheter temperature depends on variable parameters, impedance, temperature power and length of the ablation were continuously monitored. In cases where one of these parameters differed from the recommended/predicted values, treatment was automatically stopped and the tip of the catheter was repositioned.

After the procedure, patients were followed up on a regular basis at outpatient clinics of cardiology and nephrology. Monitored variables included current BP values, laboratory parameters, and evolution of health status over time. The main renal variables are identified above.

\section{Statistical analysis}

Given the small number of patients, the nonparametric paired Wilcoxon (for two measurements over time) and Friedman tests (for 3-4 repeated measurements at a time) were used for statistical analysis of data.

\section{Results}

In all cases, RSD was performed without any complications. As a rule, the procedure required a twoday hospitalization. The procedure was well tolerated by all patients, with subjective improvement (particularly in terms of reduced incidence of headache, dizziness, and increased exercise tolerance) reported by all but one patient at follow-up visits.

Table 2. Changes in renal variables post-RSD $(n=7)$.

\begin{tabular}{|c|c|c|c|c|}
\hline & Pre-RSD & 1 month post-RSD & 12 months post-RSD & \\
\hline & $\mathbf{x} \pm \mathbf{S D}$ & $\mathbf{x} \pm \mathbf{S D}$ & $\mathbf{x} \pm \mathbf{S D}$ & $\mathbf{p}$ \\
\hline$S_{c r}, \mathrm{mmol} / \mathrm{l}$ & $144.3 \pm 28.4$ & $146.4 \pm 22.1$ & $152.2 \pm 38.6$ & n.s. \\
\hline$G F R-C_{c r}, \mathrm{ml} / \mathrm{s} / 1.73 \mathrm{~m}^{2}$ & $0.92 \pm 0.63$ & $0.90 \pm 0.73$ & $0.85 \pm 0.64$ & n.s. \\
\hline GFR-MDRD, $\mathrm{ml} / \mathrm{s} / 1.73 \mathrm{~m}^{2}$ & $0.82 \pm 0.43$ & $0.78 \pm 0.37$ & $0.76 \pm 0.41$ & n.s. \\
\hline$U_{a l b / c r}, g / m o l$ & $2.72 \pm 3.18$ & $2.60 \pm 4.35$ & $2.64 \pm 3.82$ & n.s. \\
\hline$U_{N a} V, m m o l / 24 h$ & $280.2 \pm 45.4$ & $336.3 \pm 42.8$ & $240.2 \pm 36.4$ & $<0.025$ \\
\hline$U_{K} V, \mathrm{mmol} / 24 \mathrm{~h}$ & $77.7 \pm 27.3$ & $81.7 \pm 22.2$ & $68.2 \pm 31.0$ & n.s. \\
\hline$U_{\text {urea }} V, \mathrm{mmol} / 24 \mathrm{~h}$ & $437.4 \pm 150.6$ & $464.3 \pm 60.3$ & $420.3 \pm 86.2$ & 0.05 \\
\hline$F E_{N a}, \%$ & $1.44 \pm 0.36$ & $1.57 \pm 0.35$ & $1.58 \pm 0.40$ & $<0.025$ \\
\hline$F E_{K}, \%$ & $12.80 \pm 1.61$ & $11.50 \pm 3.82$ & $13.00 \pm 4.20$ & n.s. \\
\hline$U_{N a} / U_{K}$ & $3.17 \pm 1.89$ & $4.39 \pm 1.72$ & $3.52 \pm 1.68$ & $<0.025$ \\
\hline
\end{tabular}

$\mathrm{S}_{\mathrm{cr}}$ - serum creatinine, GFR-C $\mathrm{C}_{\mathrm{cr}}-$ glomerular filtration rate, $\mathrm{U}_{\mathrm{alb} / \mathrm{cr}}-$ urinary albumin/creatinine ratio, $\mathrm{U}_{\mathrm{Na}} \mathrm{V}$ - urinary sodium excretion, $\mathrm{U}_{\mathrm{K}} \mathrm{V}$ - urinary potassium excretion, $\mathrm{U}_{\mathrm{urea}} \mathrm{V}$ - urinary urea excretion, $\mathrm{FE}_{\mathrm{Na}}$ - sodium excretion fraction, $\mathrm{FE}_{\mathrm{K}}$ - potassium excretion fraction, $\mathrm{U}_{\mathrm{Na}} / \mathrm{U}_{\mathrm{K}}-$ sodium/potassium excretion ratio. 


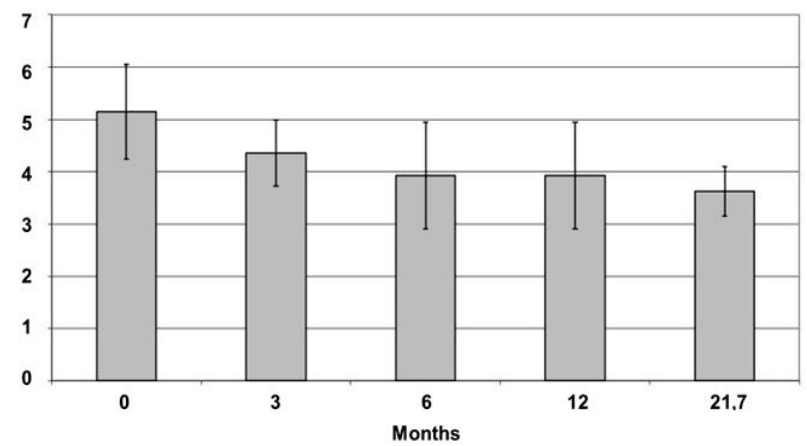

Fig. 1. Decreasing numbers of antihypertension drugs taken. All values differed statistically significantly from pre-RSD values $(p=0.05)$.

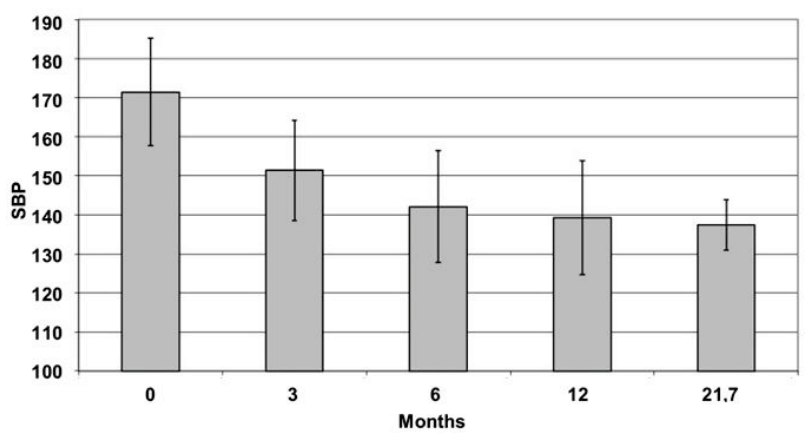

Fig. 3. Changes in systolic blood pressure (SBP) in the group of seven patients post-RSD $(\mathrm{mm} \mathrm{Hg})$. All post-RSD values differ significantly $(p=0.05)$ from pre-RDS values.

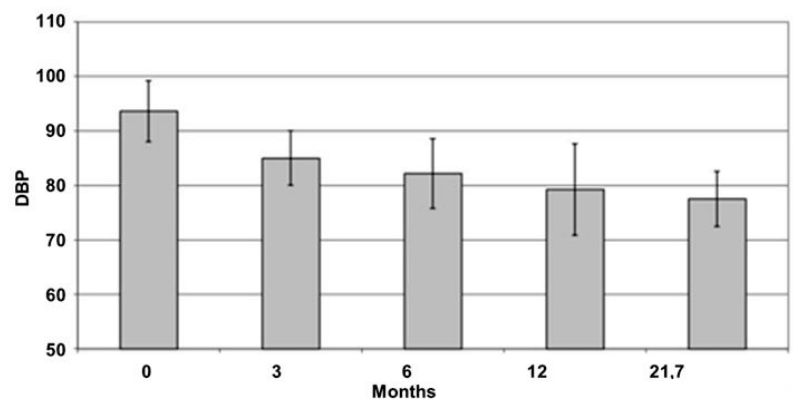

Fig. 5. Changes in diastolic blood pressure (DBP) in the group of seven patients post-RSD. All values differ statistically $(p=0.05)$ from pre-RDS values.

Likewise, there was no change in medication or the number of drugs and/or doses used even decreased (Fig. 1).

Office BP measurements in all patients at 6 months documented a decrease in SBP by at least $15 \mathrm{~mm} \mathrm{Hg}$, with the effect maintained (Fig. 2). Only one patient (VN) showed a different course on follow-up: as found later, the differences in terms of BP fluctuations were due to specific and enhanced psychological/ emotional distress. However, overall, there was a statistically significant difference between SBP and DBP levels pre-RSD and all post-procedural values $(p=0.05)$ (Figs 2, 3, 4 and 5).

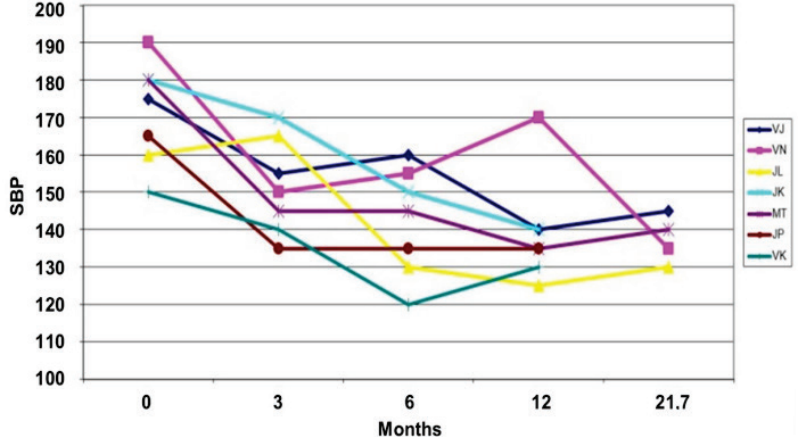

Fig. 2. Changes in systolic blood pressure (SBP) levels in individual patients post-RSD $(\mathrm{mm} \mathrm{Hg})$.

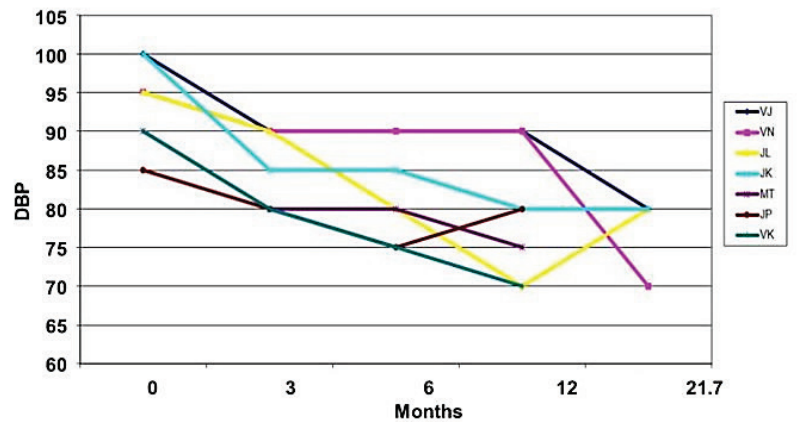

Fig. 4. Changes in diastolic blood pressure (DBP) in individual patients post-RSD $(\mathrm{mm} \mathrm{Hg})$.

Regrettably, and for a variety of reasons, ABPM values for all patients throughout the study are unavailable; given the small number of patients, it made no sense to analyze them.

No significant changes were seen in $\mathrm{GFR}_{\mathrm{cr}}$, GFR-MDRD, $\mathrm{S}_{\mathrm{cr}}$ or $\mathrm{U}_{\mathrm{alb}} / \mathrm{cr}$, not even in CKD patients. There was a significant increase in $\mathrm{U}_{\mathrm{Na}} \mathrm{V}, \mathrm{FE}_{\mathrm{Na}}$, and $\mathrm{U}_{\mathrm{Na}} / \mathrm{U}_{\mathrm{K}}(p<0.025)$, whereas urinary potassium excretion remained unchanged. The extremely high values of the fractional excretion of urea and sodium suggested high dietary protein and salt intake. Long-term (12 months) follow-up of renal function did not reveal any significant changes both in measured and estimated GFR values. However, there was a significant decrease in $\mathrm{U}_{\mathrm{Na}} \mathrm{V}$ $(p<0.025)$ reflecting the reduction of dietary salt intake (Table 2).

No statistically significant changes were noted in selected biomarkers (COP, proADM, and proANP) at the six consecutive follow-up visits.

\section{Discussion}

\section{What we do know}

Clinicians are well aware that there are individuals resistant to long-term multi-drug combination 
therapy. If disregarding a minority view that there is no such a thing as resistant hypertension, this category may include even relatively "milder" patients meeting the following criteria: use of two different antihypertensive agents (each from a different class) and a diuretic have failed to achieve adequate BP control so SBP and DBP levels do not decrease below $140 \mathrm{~mm} \mathrm{Hg}$ and $90 \mathrm{~mm} \mathrm{Hg}$, respectively (Mancia et al. 2013). In diabetic patients, the values are $10 \mathrm{~mm} \mathrm{Hg}$ lower both for SBP and DBP. In diabetic candidates for RSD, GFR should be $>45 \mathrm{ml} / \mathrm{min} / 1.73 \mathrm{~m}^{2}$.

In fact, it is widely recognized that both animals in models of arterial hypertension and patients with established hypertension show increased renal sympathetic activity (Dibona 2002). Renal sympathetic denervation procedures have been associated with $\mathrm{BP}$ reduction both in large and small laboratory animals regardless of the technique of inducing hypertension: identical outcomes have been reported for genetically modified rat populations (Katholi 1985), sodiumsensitive miniature swine (O'Hagan et al. 1990), onekidney renal hypertension (Katholi et al. 1981) and established two-kidney, one-clip Goldblatt hypertension (Katholi et al. 1982). In these animal models, just as in patients with arterial hypertension, enhanced sympathetic activity is a consistent response and can thus serve as a target for therapeutic intervention.

As such, renal denervation is a well-known approach in the management of refractory hypertension; however, while employed by surgeons in the past, it was gradually discarded because of its high morbidity and mortality rates (Smithwick and Thompson 1953, Grimson et al. 1949). The idea has only been revisited by the SYMPLICITY trials using RF ablation for RSD. Initial results were most promising with the technique quickly gaining acceptance in clinical practice (Krum et al. 2009, Esler et al. 2010, Kandzari et al. 2012). However, regrettably, the SYMPLICITY HTN-3 results (Bhatt $e t$ al. 2014) challenged the value of RSD and the technique seemed to be doomed to fall into oblivion as quickly as it became accepted. Still, a thorough search of the relevant literature clearly shows that some patients did benefit from RSD; the problem was that the investigators were unable to identify those who would (Bhatt et al. 2014, Nathan and Bakris 2014, Desch et al. 2015, Azizi et al. 2015).

\section{What we do not know}

There may be a myriad of reasons why RSD simply "failed to work" in some individuals: (a) Inadequate ablation - there is no graphic, biochemical or other piece of evidence showing that all sympathetic nerves have indeed been transected. It remains unclear whether the Medtronic device design allows all thermal energy to pass through the arterial wall. As the technique involves application of single RF pulses and given the variable course of nerve fibers, we do not know whether the course of nerves has been adequately targeted along the whole circumference of the artery (Nathan and Bakris 2014). At least some models of new-generation catheters feature a circumferential source of RF pulses thus likely eliminating this problem. Data from initial reports of small patient series are most encouraging; studies with RF techniques include the 12-month RHAS trial using a OneShot $^{\mathrm{TM}}$ device (Covidien, Culver City, CA, USA) (Ormiston et al. 2013) and 6-month follow-up within the REDUCE HTN project (Vessix V2 ${ }^{\mathrm{TM}}$ device, Boston Scientific, Natick, MA, USA) (Sievert et al. 2015).

Likewise, it is unknown whether the nerve fibers have been adequately severed. Besides, the periarterial renal innervation system is most variable and the target nerve fibers or ganglia may be located at a distance that RF pulses cannot reach (Tzafriri et al. 2014). Some reports have suggested the behavior of the sympathoadrenal plexus in the region of the kidney differs in lean individuals compared with overweight/obese ones (Lambert et al. 2007, Middlekauf 2015). Still, these and a host of other considerations, in light of the discouraging results of SYMPLICITY HTN-3, should not lead to departure from the concept of RSD once for all (Middlekauf 2015, Reddy and Olin 2014). Also, it is currently unknown whether RSD will consistently induce nerve fiber necrosis (as an irreversible type of lesion) or whether only its partial injury such as demyelinization or hypertrophy to atrophy will occur. No information is available as to the process of healing of such injured fibers and/or re-innervation. In an ovine model, re-innervation has been documented at 11 months post-RSD using a Symplicity Flex catheter (Booth et al. 2015). Furthermore, no data are available about the duration of the release of catecholamines accumulated in periarterial deposits.

The above gaps in our knowledge may contrast, for example, with a model of vincristine-based denervation, which demonstrably and reliably destroys nerve fibers both circumferentially and across the index area (based on the balloon surface) (Stefanidis et al. 2014, Stefanidis et al. 2013). 
(b) A patient may have had undiagnosed secondary hypertension.

(c) Standard BP monitoring was not performed. There is no evidence of patient compliance to drugs treatment (with only scarce data about the plasma levels of the drugs prescribed available).

Our results clearly show that RSD does have a role to play in the treatment of patients with severe hypertension. While there was decrease in SBP in all our patients, it should be acknowledged this occurred only after a substantial lifestyle modification in one patient (VN) making the effect of RSD at least disputable. Still, the decrease in BP seen after RSD in the remaining six patients is unquestionable. Among the selected novel biomarkers, a sufficient wealth of data are available about the family of natriuretic peptides, which may enhance cardiac wall stress potentially impacting a patient's prognosis in terms of developing heart failure (Sun et al. 2014).

Today, the adrenomedullin family of peptides is believed to be, among other things, a marker of vascular tone regulation (Yuan et al. 2015). While copeptin has been reported to closely reflect both SBP and DBP levels, it has been suggested copeptin may also serve as a predictor of pre-eclampsia before it becomes clinically overt (Tenderenda-Banasiuk et al. 2014, Yeung et al. 2014). However, we did not observe any consistent and statistically demonstrable changes in BP levels, either population-wide or in individuals experiencing a favorable change in BP post-RSD.

While no authoritative conclusions can be derived from our data (undoubted beneficial effect in resistant hypertension in six out of seven patients) due to the limited number of our patients, they do support the concept of RSD. In our view, the question to be asked regarding RSD should definitely not be YES or NO but IN WHOM? And, perhaps, also HOW? Needless to say, further and better designed studies using new-generation catheters are warranted to identify the patient population potentially benefitting from renal sympathetic denervation.

All procedures performed in studies involving human participants were in accordance with the ethical standards of the institutional and/or national research committee and with the 1964 Helsinki declaration and in its later amendments or comparable ethical standards.

Informed consent was obtained from all included participants.

\section{Conflict of Interest}

There is no conflict of interest.

\section{Acknowledgements}

Supported by the project Ministry of Health, Czech Republic for development of research organization 00023001 IKEM, Prague, Czech Republic - Institutional support.

\section{References}

AZIZI M, SAPOVAL M, GOSSE P, MONGE M, BOBRIE G, DELSART P, MIDULLA M, MOUNIER-VÉHIER C, COURAND PY, LANTELME P, DENOLLE T, DOURMAP-COLLAS C, TRILLAUD H, PEREIRA H, PLOUIN PF, CHATELLIER G; RENAL DENERVATION FOR HYPERTENSION (DENERHTN) INVESTIGATORS: Optimum and stepped care standardised antihypertensive treatment with or without renal denervation for resistant hypertension (DENERHTN): a multicentre, open-label, randomised controlled trial. Lancet 385: 1957-1965, 2015.

BHATT DL, KANDZARI DE, O'NEILL WW, D’AGOSTINO R, FLACK JM, KATZEN BT, LEON MB, LIU M, MAURI L, NEGOITA M, COHEN SA, OPARIL S, ROCHA-SINGH K, TOWNSEND RR, BAKRIS G: A controlled trial of renal denervation for resistant hypertension $N$ Engl J Med 370: 1393-1401, 2014.

BOOTH LC, NISHI EE, YAO ST, RAMCHANDRA R, LAMBRT GW, SCHLAICH MP, MAY CN: Reinnervation following catheter-based radio-frequency renal denervation. Exp Physiol 100: 485-490, 2015.

DESCH S, OKON T, HEINEMANN D, KULLE K, RÖHNERT K, SONNABEND M, PETZOLD M, MÜLLER U, SCHULER G, EITEL I, THIELE H, LURZ P: Randomized sham-controlled trial of renal sympathetic denervation in mild resistant hypertension. Hypertension 65: 1202-1208, 2015.

DIBONA GF: Sympathetic nervous system and the kidney in hypertension. Curr Opin Nephrol Hypertens 11: 197-200, 2002. 
ESLER MD, KRUM H, SOBOTKA PA, SCHLAICH MP, SCHMIEDER RE, BÖHM M: Renal sympathetic denervation in patients with treatment-resistant hypertension (the SYMPLICITY HTN-2 Trial): a randomised controlled trial. Lancet 376: 1903-1909, 2010.

GRIMSON KS, ORGAIN ES, ANDERSON B, BROOME RA, LONGINO FH: Results of treatment of patients with hypertension by total thoracic and partial to total lumbar sympathectomy, splanchnicectomy and celiac ganglionectomy. Ann Surg 129: 850-871, 1949.

KANDZARI DE, BHATT DL, SOBOTKA PA, O NEILL WW, ESLER M, FLACK JM, KATZEN BT, LEON MB, MASSARO JM, NEGOITA M, OPARIL S, ROCHA-SINGH K, STRALEY C, TOWNSEND RR, BAKRIS G: Catheter-based renal denervation for resistant hypertension: rationale and design of the SYMPLICITY HTN-3 trial. Clin Cardiol 35: 528-535, 2012.

KATHOLI RE: Renal nerves and hypertension: an update. Fed Proc 44: 2846-2850, 1985.

KATHOLI RE, WINTERNITZ SR, OPARIL S: Role of renal nerves in the pathogenesis of one-kidney renal hypertension in the rat. Hypertension 3: 404-409, 1981.

KATHOLI RE, WHITLOW PL, WINTERNITZ SR, OPARIL S: Importance of the renal nerves in established twokidney, one clip Goldblatt hypertension. Hypertension 4: 166-174, 1982.

KRUM H, SCHLAICH M, WHITBOURN R, SOBOTKA PA, SADOWSKI J, BARTUS K, KAPELAK B, WALTON A, SIEVERT H, THAMBAR S, ABRAHAM WT, ESLER M: Catheter-based renal sympathetic denervation for resistant hypertension: a multicentre safety and proof-of-principle cohort study. Lancet 373: 1275-1281, 2009.

LAMBERT E, STRAZNICKY N, SCHLAICH M, ESLER M, DAYWOOD T, HOTCHKIN E, LAMBERT G: Differing pattern of sympathoexcitation in normal-weight and obesity-related hypertension. Hypertension 50: 862-868, 2007.

MANCIA G, FAGARD, R, NARKIEWICZ K, REDÓN J, ZANCHETTI A, BÖHM M, CHRISTIAENS T, CIFKOVA R, DEBACKER G, DOMINCZAK A, GALDERISI M, GROBBEE DE, JAARSMA T, KIRCHHOF P, KJELDSEN SE, LAURENT S, MANOLIS AJ, NILSSON PM, RUILOPE LM, SCHMIEDER RE, SIRNES PA, SLEIGHT P, VIIGMAA M, WAEBER B, ZANNAD F: 2013 ESH/ESC Guidelines for the management of arterial hypertension: the Task Force for the management of arterial hypertension of the European Society of Hypertension (ESH) and of the European Society of Cardiology (ESC). J Hypertens 31: 1281-1357, 2013.

MIDDLEKAUF HR: A mechanistic explanation for the minimal impact of renal denervation on 24-h ambulatory blood pressure in Symplicity HTN-3. J Am Coll Cardiol 65: 959, 2015.

NATHAN S, BAKRIS GL: The future of renal denervation in resistant hypertension. Curr Hypertens Rep 16: 494-499, 2014.

O'HAGAN KP, THOMAS GD, ZAMBRASKI EJ: Renal denervation decreases blood pressure in DOCA-treated miniature swine with established hypertension. Am J Hypertens 3: 62-64, 1990.

ORMISTON JA, WATSON T, VAN PELT N, STEWART R, STEWART JT, WHITE JM, DOUGHTY RN, STEWART F, MACDONALD R, WEBSTER MW: Renal denervation for resistant hypertension using an irrigated radiofrequency balloon: 12-month results from Renal Hypertension Ablation System (RHAS) trial. Eurointervention 9: 70-74, 2013.

REDDY VY, OLIN JW: Renal denervation for resistant hypertension: not dead yet. J Am Coll Cardiol 64: 1088-1091, 2014.

SIEVERT H, SCHOFER J, ORMISTON J, HOPPE UC, MEREDITH IT, WALTERS DL, AZIZI M, DIAZCARTELLE J, COHEN-MAZOR M: Renal denervation with a percutaneous bipolar radiofrequency balloon catheter in patients with resistant hypertension: 6-month results from REDUCE-HTN clinical study. Eurointervention 10: 1213-1220, 2015.

SMITHWICK RH, THOMPSON JE: Splanchnicectomy for essential hypertension; results in 1,266 cases. J Am Med Assoc 152: 1501-1504, 1953.

STEFANIDIS C, TOUTOUZAS K, VLACHOPOULOS C, TSIOUFIS C, SYNETOS A, PIETRI P, TOUSOULIS D, TSIATIS E: Chemical denervation of the renal artery with vincristine for the treatment of resistant arterial hypertension: first-in-man application. Hellenic J Cardiol 54: 318-321, 2013. 
STEFANIDIS C, SYNETOS A, TSIOUFIS C, DRAKOPOULOU M, TSIAMIS E, TOUSOULIS D, AGROGIANNIS G, PATSOURIS E, TOUTOUZAS K: Chemical renal denervation by vincristine: the role of the flow rate of delivery. Cardiovasc Intervent Radiol 37: 1336-1342, 2014.

SUN RR, LU L, LIU M, CAO Y, LI XC, LIU H, WANG J, ZHANG PY: Biomarkers and heart disease. Eur Rev Med Pharmacol Sci 18: 2927-2935, 2014.

TENDERENDA-BANASIUK E, WASILEWSKA A, FILONOWICZ R, JAKUBOWSKA U, WASZKIEWICZSTOJDA M: Serum copeptin in adolescents with primary hypertension. Pediatr Nephrol 29: 423-429, 2014.

TZAFRIRI AR, MAHFOUD F, KEATING JH, MARKHAM PM, SPOGNARDI A, WONG G, FUIMAONO K, BÖHM M, EDELMAN ER: Innervation patterns may limit response to endovascular renal denervation. $J \mathrm{Am}$ Coll Cardiol 64: 1079-1087, 2014.

YEUNG EH, LIU A, MILLS JL, ZHANG C, MÄNNISTÖ T, LU Z, TSAI M, MENDOLA P: Increased levels of copeptin before clinical diagnosis of preeclampsia. Hypertension 64: 1362-1367, 2014.

YUAN M, WANG Q, LI C, ZHANG H, WANG H, ZHANG Y, REN J: Adrenomedullin in vascular endothelial injury and combination therapy: time for a new paradigm. Curr Vasc Pharmacol 13: 459-466, 2015. 